\title{
Nathalie Letouzé*
}

Universidade Estadual de Campinas Universidade de Brasília

\footnotetext{
* Estudante de doutorado na Universidade Estadual de Campinas (UNICAMP) e na Universidade de Brasília. E-mail: nathalieletouze@gmail.com.
} 
Resumo: Os cursos de escrita criativa podem vir a se tornar um fenômeno anglófono globalizado (DAWSON, 2005; MCGURL, 2009). Esses cursos, que se propõe a ensinar as pessoas a escreverem, sobretudo voltados à escrita narrativa ou poética, surgiram nos Estados Unidos e foram institucionalizados e amplamente difundidos após a Segunda Guerra Mundial, se expandiram para diversos países, dentre eles, o Brasil. Embora no Brasil, comparativamente, ainda sejam incipientes, nos Estados Unidos, esses cursos foram considerados o evento mais importante na história da literatura norte-americana pós-Segunda Guerra pelo pesquisador Mark McGurl (2009). A fim de compreendermos um pouco esse fenômeno, realizamos um curso de escrita criativa avançada online, cujo foco era a escrita narrativa, oferecido pela Universidade de Oxford, e fizemos um levantamento dos principais aspectos narrativos ensinados nesse curso. A título de comparação, fizemos a leitura de dois materiais que se propõe a ensinar técnicas de escrita narrativa: A jornada do herói, de Vogler (2009), e uma série de três manuais intitulados Book in a box - técnicas para romances comerciais (MCSILL e FREGONESE, 2013; MCSILL e PRIETTO, 2013 e MCSILL e PRADO, 2013). Esses materiais parecem ter um objetivo em comum, que é escrever histórias vendáveis, que sejam escolhidas e publicadas por editoras comerciais. Apesar de se poder crer que a literatura considerada de 'qualidade' esteja distante dessa discussão, esse debate merece reflexão, especialmente se levarmos em conta o quanto um escritor contemporâneo, inserido na sociedade atual, pode se distanciar dessas abordagens narrativas, uma vez que elas estão presentes não apenas em livros, mas em filmes, campanhas publicitárias, videogames, enfim, em toda parte. Diante disso, apresentaremos, nesse estudo, uma síntese das técnicas de escrita narrativa apresentadas pelos três materiais citados anteriormente e faremos isso por meio de uma comparação entre essas técnicas. Tencionamos, dessa forma, levantar e instigar reflexões a respeito desse fenômeno na sociedade e na literatura, bem como a respeito da própria narrativa em si.

\begin{abstract}
Creative writing courses may become a globalized anglophone phenomenon (DAWSON, 2005; MCGURL, 2009). These courses are intended to teach people to write, and are especially aimed at narrative or poetic writing. They emerged in the United States and were institutionalized and widely disseminated after World War II, and they have expanded to several countries, including Brazil. Although in Brazil they are still incipient, in the US, these courses are considered the most important post-WWII event in the history of American literature by researcher Mark McGurl (2009). In order to further understand this phenomenon, we took an advanced online creative writing course focusing on narrative writing offered by Oxford University and we surveyed the main narrative aspects taught in this course. By way of comparison, we also read two materials that teach narrative writing techniques: Vogler's The Writer's Journey (2009) and a series of three manuals geared towards writing comercial novels entitled Book in a box - técnicas para romances comerciais (MCSILL and FREGONESE, 2013, MCSILL and PRIETTO, 2013 and MCSILL and PRADO, 2013). These materials seem to have a common goal, which is to teach how to write saleable stories that will be chosen and published by commercial publishers. Although some may believe that the literature considered to be of 'quality' is apart from this discussion, this debate deserves reflection, especially if we take into account how far contemporary writers inserted in today's society can distance themselves from these narrative approaches, since they are present not only in books, but in films, advertising campaigns, video games, and, in short, everywhere. Therefore, we will present, in this study, a synthesis of the narrative writing techniques presented by the three previously cited materials and we will do this by comparing them. We intend, therefore, to encourage and instigate reflection on this phenomenon both in society and in literature, as well as in narrative itself.
\end{abstract}

Keywords: Creative writing; Storytelling; fictional narrative; Contemporary literature.

Recebido em 20 de julho de 2018

Aprovado em 19 de dezembro de 2018

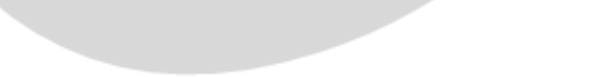

LETOUZÉ, Nathalie. O que contam os que contam sobre contar histórias. Légua \& Meia, Brasil, n. 9, v. 1, p. 226-241, 2019. 


\section{OS CURSOS DE ESCRITA CRIATIVA}

Surgidos nos Estados Unidos, os cursos chamados em língua inglesa de "Creative Writing" (Escrita Criativa) podem vir a se tornar um fenômeno anglófono mundial (DAWSON, 2005; MCGURL, 2009). Atualmente há uma pequena multidão, no Brasil e no mundo (destacadamente nos países de língua inglesa), que buscam e frequentam cursos cujo objetivo é o ensino, talvez a discussão e a prática, da escrita narrativa ou poética (AUTORA, no prelo).

Apenas a título de demonstração em relação à variedade desses cursos e ao aumento da oferta deles, comparamos as buscas que fizemos no Google em setembro de $2018 \mathrm{com}$ as que havíamos realizado em agosto de 2014. A busca pelo termo "creative writing classes" no Google, em setembro de 2018, obteve 858 mil resultados; para "creative writing course", houve 1 milhão e 300 mil resultados; e por "creative writing workshop" retornou 142.000.000. As mesmas buscas para as duas primeiras expressões realizadas em agosto de 2014 retornaram 276 mil e 371 mil resultados, respectivamente, o que evidencia um crescimento assombroso na oferta desses cursos no prazo de apenas 4 (quatro) anos. No panorama nacional, embora em número comparativamente menor, o interesse por esse tipo de curso é evidente e também espantosamente crescente. Uma busca por "aulas de escrita criativa" em setembro de 2018 retornou 132 mil resultados, enquanto que, em agosto de 2014, havia obtido reles 14.400 resultados; uma busca por "curso de escrita criativa", em setembro de 2018, retornou 82.400 resultados, enquanto que, em agosto de 2014, o resultado foi menos da metade, 37.200 resultados. Uma busca por "oficina literária", termo mais comum no Brasil, retornou 94.300 resultados em setembro de 2018. Naturalmente, há de se supor que o aumento na oferta por esse tipo de curso decorre de um aumento proporcional na demanda por eles (AUTORA, no prelo).

Esses cursos começaram a ganhar "corpo", "forma", difusão e institucionalização nos Estados Unidos a partir da década de 1930. Foi a reforma progressista na educação que propiciou o desenvolvimento e popularidade desses cursos em um momento no qual a educação tradicional estava sendo questionada. Inicialmente foram inseridos nos currículos escolares, nos quais ganharam a denominação pela qual são conhecidos atualmente, Creative Writing (Escrita Criativa). Posteriormente, marcadamente com o Iowa Writers' Workshop em 1936, embora tenha havido cursos anteriores, entraram para as universidades, se institucionalizando e se difundiram (MCGURL, 2009). Hoje, estão presentes em vários países além dos Estados Unidos, como Inglaterra, Austrália, Canadá, Nova Zelândia, Reino Unido, África do Sul e Brasil. Segundo Mark McGurl (2009), o crescimento dos programas de escrita criativa é o evento mais importante na história da literatura norte-americana pós-Segunda Guerra (AUTORA, no prelo).

A institucionalização universitária da Escrita Criativa colocou em contradição o fundamento autoexpressivo da proposta inicial desse tipo curso, pois o caráter universitário trouxe o ímpeto de se convencionalizar essa escrita devido à preocupação com a qualidade do trabalho criado. Em literatura, isso se apresenta como um complicador, uma vez que a originalidade é um valor importante nos textos cânones. Apesar de ser possível, até certo ponto, separar a instrução técnica do talento e da originalidade, como na pintura e na escultura; na literatura, os limites entre um e outro se tornam difusos (AUTORA, no prelo).

Desse modo, a pergunta que vem perseguindo os cursos de Escrita Criativa desde o princípio é: o fazer literário pode ser ensinado? (DAWSON, 2005; MCGURL, 2009). A demanda aparentemente quase insaciável por esse tipo de curso indica, no mínimo, a 
crença nessa possibilidade, ao menos na possibilidade de ensino de escrita de algum tipo de literatura, não necessariamente a canônica (MCGURL, 2009).

No Brasil, data de 1962 um dos primeiros cursos dessa natureza, ministrado pelo professor Cyro dos Anjos na Universidade de Brasília (UnB). Esses cursos, semelhantes aos cursos de Escrita Criativa em língua inglesa, no Brasil são mais frequentemente denominados como oficinas literárias, laboratórios de textos, laboratórios literários, laboratórios de criação textual ou de redação criativa (Disponível em http://www.laab.com.br/oficina.html. Consultado em 25/11/2016).

Atualmente, no âmbito universitário, destaca-se no Brasil a Oficina de Criação Literária da Pontifícia Universidade Católica do Rio Grande do Sul (PUCRS), criada em 1985 e ministrada, desde a sua criação, pelo professor Assis Brasil, a qual conta com os programas de mestrado e doutorado em Escrita Criativa e, mais recentemente, com curso de graduação também. Encontramos também o curso de graduação, habilitação em formação de escritores, da Pontifícia Universidade Católica do Rio de Janeiro (PUC-RIO) e a especialização do Instituto de Ensino Superior Vera Cruz. Propostas semelhantes de ensino de escrita narrativa ou poética podem ser encontradas, eventualmente, como disciplinas isoladas no currículo de cursos de Letras. Há também diversas oficinas desvinculadas do âmbito universitário.

A fim de mais bem compreendermos esse fenômeno dos cursos de escrita criativa, realizamos um deles, voltado para a escrita narrativa. Optamos pelo curso ofertado pela Universidade Oxford, online, de dois meses e meio de duração. Essa opção decorreu em parte pela possibilidade em si de realizarmos o curso, devido ao tempo de duração, ao fato de ser online e de ter sido disponibilizado por um valor factível e, em parte, por ser um curso ofertado por um país de língua inglesa, pois desejávamos entender as influências originais dos cursos do Brasil.

Esse curso nos chamou atenção para o fato de as técnicas ensinadas serem voltadas ao sucesso da publicação do livro por uma editora comercial e, por conseguinte, destinadas a atrair a atenção do leitor e 'facilitar' a leitura para ele. A partir disso, esse tipo de técnica, direcionadas ao apelo à atenção do leitor, tornou-se foco desse nosso estudo.

Em nossas buscas a respeito do ensino de técnicas narrativas contemporâneas, descobrimos que o material a respeito do assunto aparenta ser infinito e dar voltas ao mundo. Certamente há diferentes abordagens, diferentes conceituações teóricas e diferentes objetivos para cada um deles, de modo que tivemos de fazer escolhas do que traríamos para discussão e análise neste estudo. Optamos por trazer três materiais. $\mathrm{O}$ conteúdo desse curso de Escrita Criativa Avançada que realizamos online na Universidade Oxford. O livro A jornada do escritor, de Vogler (2009), por ser uma referência no assunto, sendo, inclusive, adotado como um dos guias padrão de Hollywood para a arte do roteiro, tanto que a revista Spy o chamou de "a nova Bíblia da indústria". Não por acaso foi traduzido para vários idiomas (dentre eles, alemão, francês, português, italiano etc) em várias edições. Por fim, também trazemos uma série de três manuais intitulados Book in a Box - Técnicas básicas para estruturação de romances comerciais. Decidimos trazer esse último para a análise em virtude de ser direta e explicitamente focada em produzir narrativas de caráter comercial, narrativas que buscam conquistar a atenção do leitor e pelo fato do autor principal dessa série, James McSill, ser um brasileiro que atua no mercado internacional, possuir um escritório em Londres e ofertar vários cursos no Brasil e no exterior. Assim, representa uma influência internacional no cenário de escritores ou aspirantes a escritores no Brasil. 
Após a leitura minuciosa dos três materiais mencionados, fizemos um levantamento dos conteúdos abordados que apontavam diretamente para o texto em si; uma vez que há também nesses materiais conteúdo motivacional para os escritores, conteúdo de preparação para a escrita e conteúdo referente ao processo de publicação, dicas, dentre outros. A partir desse levantamento, buscamos verificar quais desses conteúdos abordados nos três materiais, referentes ao texto, poderiam ser equiparados, se seriam, de algum modo, semelhante. Em seguida, construímos o quadro apresentado a seguir. Após o quadro, faremos explicações de cada um dos itens enumerados:

\begin{tabular}{|c|c|c|c|}
\hline & Curso online em universidade ${ }^{2}$ & Vogler & McSill \\
\hline 1 & Personagens complexos. & Uso de arquétipos. & $\begin{array}{l}\text { Personagem é o elemento } \\
\text { principal da narrativa. }\end{array}$ \\
\hline 2 & Nêmesis. & Sombra. & $\begin{array}{l}\text { Antagonista (obstáculo ao } \\
\text { protagonista). }\end{array}$ \\
\hline 3 & Importância do diálogo. & & Importância do diálogo. \\
\hline 4 & $\begin{array}{l}\text { Toda narrativa deve ter um } \\
\text { Nêmesis. }\end{array}$ & $\begin{array}{l}\text { Poder do desejo - o } \\
\text { herói quer algo. }\end{array}$ & $\begin{array}{l}\text { História - protagonista quer algo } \\
\text { e encontra obstáculos. }\end{array}$ \\
\hline 5 & Estrutura em 3 atos. & Estrutura em 3 atos. & Estrutura em 3 atos. \\
\hline 6 & $\begin{array}{l}\text { Ponto de virada e/ ou reviravolta } \\
\text { inesperada. }\end{array}$ & $\begin{array}{l}\text { Ponto de virada e/ ou } \\
\text { ponto de não retorno. }\end{array}$ & Pontos de virada. \\
\hline 7 & Trama secundária. & Jornada do herói. & $\begin{array}{l}\text { Alternativa à estrutura em } 3 \text { atos: } \\
\text { clássica estrutura de } 10 \%, 25 \% \text {, } \\
50 \%, 75 \%, 90 \%, 100 \% \text { i }\end{array}$ \\
\hline 8 & & Polaridade. & \\
\hline 9 & & Ponto de não retorno. & Ponto de não retorno. \\
\hline 10 & Tema. & & Tema. \\
\hline 11 & Tipo de história. & & \\
\hline 12 & Cena. & & Cena. \\
\hline 13 & Mostrar em vez de contar. & & Mostrar em vez de contar. \\
\hline 14 & PDV da cena. & & PDV da cena. \\
\hline 15 & & & Filtro emocional. \\
\hline 16 & & & Filtro de cena. \\
\hline 17 & Foco narrativo. & & Foco narrativo. \\
\hline 18 & Descrição. & & \\
\hline 19 & Metáforas. & & \\
\hline
\end{tabular}

Fonte: Elaborado pela autora.

O item 1 do quadro é referente à complexidade dos personagens e é tratado nos três materiais, cada qual abordando o tema com suas particularidades e nuances, mas todos destacando a importância dos personagens nas narrativas. $\mathrm{O}$ texto de McSill e Prietto (2013), o mais direto, diz que o personagem é o elemento principal e essencial da narrativa e que, se a história for a respeito de um animal ou alguma outra coisa, deve estar antroporfomizada. Segundo colocam, o leitor deve se envolver com o personagem a ponto de torcer por ele, viver e sentir a vida dele. Apresentam os personagens como sendo planos ou esféricos e conforme a "função" que desempenham na narrativa: protagonista, antagonista, vilão (que pode ou não ser o antagonista), coprotagonista e coadjuvante. $O$ antagonista é algo ou alguém que se contrapõe ao protagonista (pode ser um evento climático, por exemplo); vilão é um personagem que se opõe ao protagonista, pode ser o vilão principal, nesse caso, o antagonista, ou pode ser um personagem que conflita com

\footnotetext{
${ }^{1}$ Quadro apresentado na Abralic 2018.

${ }^{2} \mathrm{O}$ conteúdo do quadro referente ao curso da Oxford foi primeiramente apresentado no Gel 2018.
} 
o protagonista momentaneamente. Destacam, quando falam dos personagens, que a história deve ser mais 'mostrada' por meio do que acontece com os personagens do que 'contada'.

Vogler (2009) também destaca a importância dos personagens na história justamente pela identificação do leitor/espectador com eles. Exatamente por isso, traz a questão dos arquétipos, por ser por meio dessas 'personalidades' universais que mais facilmente criamos vínculos emocionais com as narrativas. Define arquétipos como "personagens ou energias que se repetem constantemente e surgem nos sonhos de todas as pessoas e mitos de todas as culturas." (VOGLER, 2009, p. 42). Segundo Jung, na descrição de Vogler (2009), os personagens repetidos do mito mundial são os mesmos que aparecem nos sonhos e fantasias das pessoas, por isso, Vogler (2009) explica que histórias com personagens arquetípicos são psicologicamente verossímeis ao leitor/espectador, ainda que em um universo imaginário, e criam identidade com quem lê a história ou assiste a ela.

Segundo Vogler (2009), os arquétipos parecem incrivelmente constantes com o passar do tempo e das culturas. O conceito de arquétipos, para este autor, é indispensável para entender o objetivo e função dos personagens em uma história, de modo que é uma das ferramentas mais poderosas na 'maleta de truques' do narrador moderno. Ele considera os arquétipos a partir da observação do especialista russo em contos de fadas, Vladimir Propp, como funções desempenhadas pelos personagens para alcançarem determinados objetivos, e não papéis fixos e rígidos. Essa flexibilidade dos personagens de exercerem diferentes arquétipos de acordo com o momento da narrativa traz maior liberdade à arte de narrar, segundo Vogler (2009).

Os arquétipos mais úteis e recorrentes nas narrativas, na opinião de Vogler (2009), são: heróis; mentor; guardião do limiar; camaleão; sombra; arauto; aliado; pícaro. Embora existam muitos outros arquétipos, estes seriam os básicos a partir dos quais os outros são modelados. Duas são as questões que norteiam a identidade arquetípica: qual função psicológica ou parte da personalidade o arquétipo representa e qual a sua função dramática na história.

Herói: descreve um personagem central ou protagonista de qualquer gênero. É o personagem disposto a sacrificar suas próprias necessidades em favor dos outros. Representa a busca pela identidade e totalidade do ego. Suas funções dramáticas são: criar identidade com a audiência; aprender ou amadurecer; agir (geralmente é quem move a história adiante); ter disposição para o sacrifício; enfrentar a morte (real ou simbólica).

Mentor (velho sábio ou velha sábia): em geral é um personagem positivo que ajuda ou treina o herói. Funções dramáticas: ensinar, dar presentes que servirão ao herói em sua jornada, como poção mágica, ferramentas, utensílios mágicos etc. Pode ser também a consciência do herói ou mesmo aquele quem o motiva a seguir a jornada que lhe foi proposta.

Guardião do limiar: nas palavras de Vogler, "Em cada portal para um novo mundo, existem guardiões poderosos no limiar, prontos a impedir que os indignos entrem.” (p. 91). Em geral, não são os principais vilões ou antagonistas da história, mas podem ser aliados ou subalternos aos vilões. Psicologicamente representam nossas neuroses, medos, vícios, cicatrizes emocionais, que impedem nosso avanço. Função dramática: testar o herói.

Arauto: esse tipo de personagem apresenta desafios e anuncia a iminência de mudanças significativas. Função psicológica: chamar o herói à mudança. Função dramática: motivação, já que oferece ao herói um desafio e, por conseguinte, coloca a história em movimento. 
Camaleão: a natureza do camaleão é ambígua, é a mudança e a instabilidade. Segundo Vogler (2009), quase sempre o par romântico do herói manifesta as características do camaleão. O camaleão muda de aparência e humor, sendo difícil definilos. Função psicológica: expressa a energia do feminino e do masculino. Função dramática: traz dúvida e suspense à história.

Sombra: lado obscuro, aspectos não expressos, desconhecidos ou rejeitados. Nas histórias, a sombra é projetada pelos vilões, inimigos em geral. Função psicológica: exprime sentimentos reprimidos, traumas profundos ou culpa. Faz a vez das psicoses. Função dramática: desafiar o herói e lhe dar um oponente digno de ser combatido.

Aliado ou aliados: podem cumprir diversas funções junto ao herói, como companheiro, parceiro de treino, consciência ou alívio cômico. Função psicológica: podem representar as partes não expressas ou não utilizadas da personalidade que devem ser acionadas para que façam seu trabalho.

Pícaro: traz a energia da travessura e do desejo de mudança. Função psicológica: reduzem egos inflados e colocam os pés dos heróis e do público no chão. Trazem mudança e transformação. Função dramática: trazer alívio cômico à história.

Vogler (2009) destaca ainda que humanizar os personagens aumenta a identificação do público com eles. Nesse sentido, sugere, por exemplo que o herói apresente alguns defeitos, enquanto o vilão, algumas qualidades.

No curso de Oxford, personagens é o conteúdo de duas unidades. Na verdade, é o único assunto proposto como o foco principal de duas unidades, ou seja, considerando um conjunto de dez unidades, o fato de esse assunto ser tratado em duas unidades distintas demonstra a relevância atribuída aos personagens. Na terceira unidade, enfoca-se o protagonista, e na quarta os personagens de suporte, dentre eles e com especial destaque, o que chamam de Nêmesis, o antagonista, para McSill (2013), ou a Sombra, para Vogler (2009). A história deve ser contada por meio de ações e pensamentos plausíveis de personagens complexos, os quais, por sua vez, devem ser verossímeis e, para isso, precisam de uma aparência externa e um interior psicológico completos. Devem ter qualidades, bem como defeitos e segredos. Deve haver tensão/ conflito entre seus sentimentos e ações externas; devem ter um histórico de vida.

$\mathrm{Na}$ quarta unidade, é abordado que os protagonistas, assim como as pessoas, seriam mais bem definidos por como reagem/ respondem a outras pessoas/ personagens, uma vez que são seres sociais. A diferença entre protagonista e personagem secundário é que os primeiros movem a narrativa, a ação, enquanto os segundos comentam a ação. Todavia os secundários também precisam ter vida própria interessante para serem personagens que despertam a atenção dos leitores e proporcionam interações instigantes com o protagonista. Nessas duas unidades, 3 e 4, recomendaram a leitura dos capítulos do livro de Vogler (2009) a respeito do arquétipo do herói e do arquétipo da sombra, respectivamente.

Verificamos desse modo que os três materiais falam mais ou menos o mesmo a respeito dos personagens ou, pelo menos, dão a mesma importância a eles nas narrativas.

O item 2 do quadro é a respeito do que se interpõe entre o protagonista e a conquista de seus anseios, ou seja, o antagonista, a sombra ou o nêmesis. Esse pode ser um desdobramento do item anterior, personagem ou não. Pode estar representado por uma força externa e não personificada, como uma condição climática, uma doença etc. Quando for um personagem, segundo o curso de Oxford, deve ser quase tão complexo quanto o protagonista. Vogler (2013) diz algo semelhante ao dispor que, assim como o protagonista deve ter alguns defeitos para ser humanizado, a sombra deve ter algumas qualidades. McSill e Prietto (2013) destacam a função do antagonista ao defini-lo como "um 
propulsor do conflito principal da estória, se opondo ao grande objetivo do protagonista" (p. 28). No item 4 do quadro, veremos que esses mesmos autores resumem a história como sendo: o protagonista quer algo e encontra obstáculos. Assim, de acordo com esse entendimento, o antagonista é tão importante quanto o herói para que exista a história e é basicamente o que defendido nos três materiais de uma forma ou de outra.

No item 3, Oxford e McSill e Fregonese (2013) destacam a importância do diálogo para a narrativa. Oxford resume a questão colocando que personagens são definidos pelo que dizem, pelo o que não dizem e pela maneira como dizem. É um item que Vogler (2009) não aborda, porém, vale destacar que, originalmente, A jornada do escritor foi escrito para ser um guia de análise de roteiros em Hollywood, de modo que o diálogo já seria condição sine qua non.

O item 4 é interessante: McSill e Fregonese (2013) resumem o que seria uma história com a frase "protagonista quer algo e encontra obstáculos" e destacam que, para a narrativa se manter interessante para o leitor, o protagonista deve ser constantemente frustrado em suas tentativas de obter o que deseja. Uma vez que o conflito principal da narrativa estiver resolvido, o leitor perde interesse nela. E isso é levado ao extremo na estrutura proposta por McSill e Fregonese (2013), cada cena deve ser construída dessa forma: alguém querendo algo e tendo obstáculos para conseguir.

Vogler (2009) coloca isso de um modo um pouco diferente, menos resumido, porém, na prática, seria a mesma coisa. Para Vogler (2009), a história trata de um herói que sai em uma jornada em busca de algo (que seria o 'querer algo') e encontra desafios/ provações para conseguir isso ('obstáculos'). Todavia Vogler (2009), baseado nos estudos de Campbell (2007), afirma que todo esse processo ocorre em 12 passos, a chamada jornada do herói, embora nem toda história tenha que necessariamente seguir exatamente os 12 passos, nem tampouco deva seguir a ordem de eventos apresentada. Segundo Vogler (2009), essa seria tão somente a estrutura mais comum e mais eficaz nas narrativas,.

Na terceira edição, Vogler (2009) ressalta a busca do herói e a constante frustração dessa busca no tópico O poder do desejo, em que aborda diretamente o mesmo que McSill e Fregonese (2013). O desejo do herói pode ser um objetivo na narrativa e, como tal, uma força motriz na história. A intenção é fazer com que o público se identifique com a heroína/ o herói e passe a compartilhar aquilo que ela/ ele deseja. Porém, a maior parte da narrativa é construída a partir das frustrações de possibilidades da heroína/ do herói atingir seu objetivo, fazendo parecer ao público que não conseguirá o que busca.

O curso de Oxford, é interessante destacar, tem como uma de suas referências bibliográficas o livro de Vogler (2009), entretanto, apesar de indicar a leitura do capítulo que descreve a jornada do herói, no texto da plataforma, nem os arquétipos, nem a questão do desejo são abordados diretamente ou com ênfase. Os exercícios sugeridos também não enfocam essas questões. Há um destaque, tanto no conteúdo, quanto nos exercícios propostos, de que o autor inclua em sua narrativa um nêmesis, ou seja, aquele que representa o obstáculo, quem se opõe ao protagonista, sendo considerado um elemento essencial da narrativa.

$\mathrm{O}$ item 5 do quadro, a estrutura em 3 atos, é abordado em todos os materiais, entretanto, cada um a sua maneira.

A estrutura em 3 atos segundo o curso da Universidade Oxford corresponde a: $1^{\mathrm{o}}$ ato - introdução dos personagens e do ambiente, apresentação de ambiguidades e possíveis conflitos, ocorre o $1^{\circ}$ ponto de virada; $2^{\circ}$ ato - desenvolvimento dos personagens e do ambiente, narrativa se desenvolve sobre o que ocorreu no $1^{\circ}$ ponto de virada, ocorre o $2^{\circ}$ ponto de virada (crise); $3^{\circ}$ ato - resolução da crise, $3^{\circ}$ ponto de virada (escolha moral). 
Estrutura em 3 atos para Vogler corresponde a: $1^{\circ}$ ato: apresentação da história (personagens, conflito, situação inicial) e termina com a decisão definitiva do herói de embarcar na jornada (esse é chamado por Vogler (2009) como um ponto de não retorno, mas é equivalente a um ponto de virada); $2^{\circ}$ ato: o herói encontra desafios e provas, fazendo aliados e inimigos. Enfrenta o conflito principal e é recompensado (nesse ponto termina o segundo ato); $3^{\circ}$ ato: o herói retorna a sua vida anterior, porém modificado.

A estrutura em 3 atos para McSill e Fregonese (2013) corresponde a: $1^{\circ}$ ato: apresentação do personagem; $2^{\circ}$ ato: conflito principal da história; $3^{\circ}$ ato: personagem passa pelo clímax atingindo ou não o objetivo principal da história.

A estrutura em 3 atos conforme apresentada pelo curso de Oxford se assemelha bastante àquela exposta por McSill e Fregonese (2013) e ambas diferem da apresentada por Vogler (2009), porquanto, para Vogler (2009), o terceiro ato corresponde ao retorno do herói para o 'mundo comum', para a situação inicial, depois de o conflito principal da narrativa ter sido resolvido no segundo ato. Conforme os textos do curso de Oxford e do livro de McSill e Fregonese (2013), o conflito só seria resolvido no terceiro ato.

Pontos de virada, item 6 do quadro, são momentos decisivos na história, que podem mudar completamente a perspectiva do leitor/ espectador a respeito da história, com a revelação de um segredo, por exemplo. Trata-se, pois, daqueles momentos em que o leitor/espectador é apresentado a uma determinada situação que 'não é o que parecia ser', Oxford chama isso de reviravolta inesperada. Para o curso de Oxford, a reviravolta inesperada deve ser construída na narrativa sutilmente, com algumas dicas que não sejam óbvias. Se for algum segredo, deve ser algo que seja 'forçado' a aparecer na narrativa pela força dos eventos.

Os três materiais trazem 'outros olhares' a respeito da estrutura da trama, que se configura como o item 7 do quadro. O curso de Oxford sugere o desenvolvimento de uma trama secundária para enriquecer a narrativa, tornar a história mais interessante. Essa trama secundária segue paralela à trama principal e, em geral, pode proporcionar alívio cômico na história e/ou comentar a trama principal.

Vogler (2009) detalha a estrutura em três atos com a jornada do herói. Embora infinitamente variável, a história de uma heroína/de um herói é sempre uma jornada. Ela/ele sai de um ambiente confortável, conhecido, e parte para um mundo desconhecido e desafiador. Pode ser uma jornada externa, ou seja, rumo a um ambiente real, como pode ser uma jornada interior, da mente, do coração ou do espírito. "Em qualquer história, o herói cresce e se transforma, empreendendo uma jornada de um modo de ser para outro" (Vogler, 2009, p. 45).

Segundo Vogler, os estágios da jornada do herói surgiriam naturalmente, mesmo sem a consciência do escritor, porém o uso consciente do que chama "guia antiquíssimo" potencializaria a capacidade de se contar histórias 'melhores'. A jornada do herói, na transposição de Vogler (2009) para indústria do entretenimento, resumidamente seria:

Primeiro Ato: $1^{\circ}$ Estágio da jornada do herói - Mundo Comum. A maioria das histórias tira a/o personagem principal (a heroína/ o herói) do mundo comum e a/o leva a um mundo especial, onde a maior parte da aventura ocorre e onde a heroína/ o herói irá, em geral, crescer como personagem. $2^{\circ}$ Estágio da jornada do herói - Chamado à aventura. O herói se vê diante de um problema, desafio ou aventura, ao qual Vogler (2009) se refere como sendo o 'chamado'. Uma vez consciente desse 'chamado', o/a protagonista não pode mais permanecer inerte no mundo comum. $3^{\circ}$ Estágio da jornada do herói - Recusa do chamado (herói relutante). Esse estágio é definido pelo medo. É o momento em que o herói pode hesitar em seguir o chamado à aventura ou mesmo recusálo. Nesse momento, algo mais pode acontecer que motive a heroína/ o herói a ingressar 
na aventura. $4^{\circ}$ Estágio da jornada do herói - Mentor: velha sábia ou velho sábio. Muitas histórias já terão apresentado um mentor à heroína/ ao herói nessa fase, que pode vir figurado em um velho sábio, um feiticeiro etc. ou pode ter outras roupagens. A função do mentor é preparar o herói para enfrentar o desconhecido, o mundo da aventura. Entretanto, o mentor só pode acompanhar o protagonista até certo ponto da jornada. $5^{\circ}$ Estágio da jornada do herói - Travessia do primeiro limiar. É nesse momento que a heroína/ o herói se compromete com a aventura. Ele aceita o desafio e a aventura começa.

Segundo Ato: $6^{\circ}$ Estágio da jornada do herói - Provas, aliados e inimigos. No mundo especial, o herói encontra desafios e provas e, no processo, faz aliados e inimigos e "começa a aprender as regras do Mundo Especial" (p. 51). $7^{\circ}$ Estágio da jornada do herói - Aproximação da caverna secreta. O herói se aproxima do local (literal ou figurado) de onde está o cerne da história, onde está o objetivo da missão, ao qual Vogler (2009) se refere como sendo a 'caverna'. É no limiar da 'caverna' que os heróis se detêm para se preparar para o desafio maior, se planejar, 'enganar os soldados do vilão' etc. $8^{\circ}$ Estágio da jornada do herói - Provação. O herói enfrenta seu maior medo. Nesse estágio ocorre uma definição na narrativa. $9^{\circ}$ Estágio da jornada do herói - Recompensa. Nesse momento, o herói toma posse do que era seu objetivo na missão, da sua recompensa. Pode ser também a solução de um conflito.

Terceiro Ato: $10^{\circ}$ Estágio da jornada do herói - O caminho de volta. Logo no início do terceiro ato, o herói ainda está no mundo especial e deve retornar, a partir de suas conquistas, ao mundo comum. Às vezes há ainda reconciliações a serem feitas ou, no próprio trajeto de retorno ao mundo comum, perseguições. $11^{\circ}$ Estágio da jornada do herói - Ressurreição. Nos mitos antigos, nos tempos antigos, caçadores e guerreiros precisavam se purificar antes de retornarem à comunidade. É como se o herói precisasse renascer, ser depurado em uma última provação de morte e ressurreição antes de voltar a viver no mundo comum. $12^{\circ}$ Estágio da jornada do herói - Retorno com o Elixir. O herói retorna ao mundo comum, mas a jornada só tem sentido se trouxer consigo o tesouro conquistado, a lição aprendida, alguma contribuição ao mundo comum.

Vogler (2009) chama a atenção para o fato de a jornada do herói ser uma estrutura em esqueleto a ser preenchida com os detalhes de cada narrativa, mas que não deve ser seguida com precisão absoluta. A importância maior está nos valores dos personagens.

McSill e Fregonese (2013) descreve a estrutura clássica como: 10\%: colocação do conflito; $25 \%$ como a apresentação do $1^{\circ}$ ponto de não retorno do protagonista; $50 \%$ escalada do conflito e $1^{\circ}$ ponto de virada; $75 \%$ como a apresentação do $2^{\circ}$ ponto de virada, o conflito deve se intensificar; $95 \%$ deve ocorrer o clímax; 100\% mostrar a vida do protagonista depois do conflito. Os autores apresentam essa estrutura para a narrativa como sendo uma alternativa à estrutura em 3 atos. A diferença principal que observamos entre essa estrutura e aquela em 3 atos proposta por esses mesmos autores é que, nessa estrutura denominada clássica, o conflito é apresentado logo no início, sendo intensificado ao longo da história e resolvido perto do final e há uma parte da história destinada a mostrar a vida do protagonista após a resolução do conflito, o que não é apontado na estrutura em 3 atos também proposta pelos autores. Essa estrutura clássica nos parece ser um meio termo entre a estrutura em 3 atos apresentada por Vogler (2009) e a estrutura em 3 atos apresentada por McSill e Fregonese (2013).

Esses sete primeiros itens foram os que encontramos maior equivalência nos três materiais. Os próximos itens foram abordados em apenas um ou dois dos materiais.

O item 8 é a respeito da polaridade. Vogler (2009) considera um princípio essencial da narrativa, por criar tensão e movimento. Por exemplo, se uma narrativa é a 
respeito da honestidade, isso, automaticamente, evoca a desonestidade. O item 9 é tratado em Vogler (2009) e McSill e Fregonese (2013). Trata-se do 'ponto de não retorno'. Refere-se a acontecimentos que colocam a narrativa em uma situação em que as coisas não 'podem mais voltar a ser como antes', algo muda. Segundo Vogler (2009), do primeiro ato para o segundo, há um ponto de não retorno, algo que coloca o herói definitivamente na aventura.

O material do curso de Oxford e McSill (2013) defendem que toda narrativa precisa ter uma premissa ao redor da qual se constitua, denominada como o tema, prevista no item 10 do quadro. A diferença entre trama e tema, segundo Oxford, é que a primeira é a ação na história, o enredo; enquanto o segundo, o tema, é a ideia por trás dessa ação. Uma trama sem tema seria uma sequência de ações incompatíveis; um tema sem trama seria um ensaio teórico, uma filosofia abstrata.

Além do tema, no curso de escrita criativa é entendido que é preciso saber qual é o tipo de história que se escreve, por exemplo, ficção científica, comédia romântica, terror etc., mas que é possível subverter a expectativa do leitor com relação a isso, criando, por exemplo, um conto de fadas em um contexto de ficção científica, item 11 do quadro.

McSill (2013) aborda com bastante minúcia e importância o conceito de cena, item 12. Para esse autor, cena é unidade básica da história, deve servir a dois fins: o primeiro, mover a história; o segundo, revelar o cenário, revelar personagem. Pode ser de ação ou de reação. A estrutura de uma cena de ação é alguém quer algo e encontra obstáculos para conseguir; enquanto a cena de reação (ou sequela) ocorre depois da cena de ação e tem a seguinte estrutura: reflexão do personagem, dilema, tomada de decisão, a qual, por sua vez, faz entrar em uma nova cena de ação. Cena de ação mais uma cena de reação (sequela) formam um ciclo completo na narrativa. Os textos do curso online apresentavam várias vezes os termos 'cena' e 'reação interna do personagem' para se referir a algo que aconteceu na história, e utilizam sobretudo nas orientações dos exercícios, para que os textos escritos tivessem 'uma ação externa do personagem e uma reação interna', porém o assunto não é abordado de fato conceitualmente. O próprio termo 'cena' e as conceituações de McSill (2013) a respeito nos fazem pressupor que essa abordagem narrativa decorre de técnicas de escrita de roteiro. Talvez por isso Vogler (2013) não trate desse tópico, por ser assunto provavelmente bastante evidente na indústria cinematográfica desde a época que escreveu o livro.

Um dos tópicos tratados com destaque no curso de Oxford e por McSill (2013) é o conceito de 'mostrar em vez de contar', do inglês Show don't tell. Segundo o pesquisador especialista em literatura norte-america contemporânea Mark McGurll (2009), esse é um dos princípios da fase inicial dos cursos de escrita criativa, sendo, inclusive, o título do segundo capítulo de seu livro The program Era. Esse princípio, ainda segundo McGurl (2009), teria suas origens no método cênico do teatro jamesiano e representou a incorporação profunda das técnicas de escrita teatral na narrativa poética. Para esse autor, esse princípio poderia ser parafraseado por dramatize don't generalize (dramatize, não generalize).

Esse princípio é explicado tanto no material do curso de escrita criativa quanto nos manuais de McSill (2013) como a história devendo ser narrada por meio de ações e diálogos dos personagens, devendo-se, pois, evitar explicar, analisar a história. É algo que, no nosso entendimento, traz dinamicidade à narrativa e, assim como o conceito de cena, a aproxima da arte cinematográfica/ teatral. No terceiro manual de McSill e Prado (2013), há uma recomendação, inclusive, de termos, tipos de advérbios e adjetivos que não devem ser utilizados na narrativa por 'contarem mais do que mostram', dentre essas 
recomendações estão: não usar os verbos ser, estar, ficar, sentir; evitar o uso de advérbios de modo terminados em 'mente'; eliminar adjetivos que 'contem mais do que mostrem'.

Quanto ao item 14, 'ponto de vista da cena', tanto o material do curso online quanto os manuais de McSill (2013) abordam esse tópico da seguinte forma: cada cena deve ser narrada predominantemente da perspectiva de um dos personagens apenas; não se deve alternar esse ponto de vista de um personagem a outro sem alguma marca de transição. Não se pode, por exemplo, dizer o que o personagem A sentiu e, em seguida, dizer o que o personagem B sentiu. É preciso, antes, colocar alguma transição nas ações dos personagens, nos elementos do cenário ou na própria cena, a fim de que se possa descrever as emoções e pensamentos de outro personagem. O contrário poderia 'confundir' o leitor. McSill (2013) faz a ressalva de um escritor experiente poder fazer isso, porém, ainda assim, deve ser usado com cautela, para se evitar ambiguidades.

Os itens 15 e 16 são conceitos abordados apenas por McSill (2013). Ele denomina o item 15 de 'Filtro emocional' e define como sendo a qualificação, pelo personagem PDV (personagem que detem o ponto de vista da cena), de tudo que o cerca baseado em seu contexto de vida, sua história. Trata-se, pois, do modo como o personagem interpreta e entende os eventos e reage a eles a partir de sua própria experiência pessoal.

O item 16, filtro de cena, se refere aos elementos que modificam a percepção do ambiente em uma cena. Por exemplo, um personagem míope que esteja sem óculos poderá não identificar outros personagens que entrem no ambiente.

$\mathrm{O}$ item 17, foco narrativo, refere-se às opções de narrador. $\mathrm{O}$ material disponibilizado no curso online coloca que a escolha do foco narrativo é algo de fundamental importância, uma vez que o narrador é a perspectiva do leitor (a visão de abordagem) na história. Sob essa perspectiva, o narrador pode ser em primeira pessoa, terceira pessoa, narrador personagem, terceira pessoa, narrador onisciente ou uma mistura da primeira pessoa com o narrador em terceira pessoa onisciente. McSill (2013) menciona os três tipos de narrador, mas atribui importância menor a isso.

Os itens 17 e 18 são abordados apenas pelo curso de escrita criativa, segundo o qual tanto as descrições quanto as metáforas funcionam na narrativa para se colocar algo em foco para o leitor, seja um personagem, um tema ou a própria trama. Quanto às descrições, quanto mais simples forem, melhor. Quanto às metáforas, elucidam que uma boa metáfora pode substituir 50 palavras, porém, deve-se tomar o cuidado de evitar metáforas clichês, contraditórias ou confusas.

\section{CONSIDERAÇÕES FINAIS}

Apesar de se poder crer que a literatura considerada de 'qualidade' esteja distante dessa discussão, esse debate merece reflexão, especialmente se levarmos em conta o quanto um escritor contemporâneo, inserido na sociedade atual, pode se distanciar, conscientemente ou não, dessas abordagens narrativas, uma vez que elas estão presentes não apenas no que se considera 'literatura comercial' ou 'baixa literatura', mas em filmes, campanhas publicitárias, videogames, enfim, em toda parte. Assim, ainda que um escritor contemporâneo não tenha cursado nenhum desses cursos, lido nenhum material a respeito, esteja isento de uma influência direta, possivelmente não o está de uma influência indireta.

Outra questão a se considerar é que a escrita de textos literários com a intenção de agradar ao público não é novidade. Os romances de folhetim são exemplos de literatura escrita intencionalmente para atrair leitores vender jornais. Naquela época, os escritores 
com maior capacidade de seduzir leitores, eram disputados pelos jornais a altos preços (MEYER, 2005). Edgar Allan Poe admite, em A filosofia da composição, ter escrito o poema $\mathrm{O}$ corvo com a intenção de agradar "ao gosto do público e da crítica" e, nesse ensaio, descreve e justifica as escolhas que fez na escrita do poema tendo esse objetivo em mente.

Miguel de Cervantes (2002), no prólogo de Dom Quixote, defende que o texto deve emocionar o leitor, agradá-lo, fazer "rir o melancólico, gargalhe o risonho, não se enfade o simplório, se admire o discreto do invento, não o despreze o grave, nem deixe o prudente de louvá-lo" e, para isso, basta que os períodos sejam sonoros e festivos, simples e claros, com palavras expressivas, e clareza nos conceitos, esclarecendo-os ao invés de obscurecê-los. Nesse prólogo, Cervantes contrapõe a narrativa de Dom Quixote com os demais romances de cavalaria, repletos de citações de filósofos e escritores considerados importantes. Dizendo que o romance, ao invés de obscurecer conceitos, deve clareá-los, mesmo explicá-los para o leitor, que a narrativa deve ser simples e clara, porém tocante, emocionante. Essas colocações de Cervantes são semelhantes ao que se pretende com as técnicas de escrita ensinadas nos três materiais que analisamos, ou seja, se conectar com o leitor, fazê-lo rir ou chorar, fazê-lo sentir-se o protagonista, como coloca McSill (2013).

A diferença entre esses autores, os romances de folhetim e os materiais que analisamos na nossa opinião, são sobretudo duas: a consciência cada vez mais definida e clara das técnicas narrativas que produzem essa conexão emocional com o leitor, que o agradam e fazem com que se sinta engajado com o texto e 'não consiga parar de ler' e a larga escala em que isso está sendo difundido atualmente nesses cursos de escrita criativa e em todo o material disponibilizado sobre o assunto. Essas técnicas narrativas demonstraram tamanha capacidade de envolver o público que estão sendo utilizadas pelo universo do marketing (XAVIER, 2015). Foi descoberto que as narrativas tem o potencial para venderem muito mais do que a si mesmas e, em nossas buscas pelas características das narrativas que têm mais força de apelo junto ao público, descobrimos a força própria da narrativa em si.

Barthes (2011) aponta que "a narrativa está presente em todos os tempos, em todos os lugares, em todas as sociedades; a narrativa começa com a própria história da humanidade (BARTHES, 2011, p. 19). Harari (2018), doutor em história pela Universidade de Oxford, comprova essa colocação. Segundo ele, a estatueta de marfim de "homem leão' ou "mulher leoa", da caverna de Stadel, é o primeiro registro histórico da mente humana ser capaz de imaginar coisas que não existem. Essa estatueta data de 32 mil anos atrás.

Ainda de acordo com esse autor, a fofoca, que podemos considerar como uma narrativa sobre o outro, representa uma das teorias de como a nossa linguagem evolui de modo singular, diferenciando-se da lingugem de outros animais e de outros Homo anteriores aos Sapiens. De acordo com essa teoria, a nossa linguagem evoluiu como um meio de partilhar informações, e as informações mais importantes em um bando é "quem odeia quem, quem está dormindo com quem, quem é honesto, quem é trapaceiro." (HARARI, 2018, p. 31). E, embora a fofoca não seja algo bem visto, "é essencial para a cooperação em grande número" (HARARI, 2018, p. 32). Por mais curioso que essa teoria possa parecer, é reforçada por vários estudos (HARARI, 2018).

Esse autor argumenta ainda que a característica verdadeiramente mais única da nossa linguagem não é a capacidade de transmitir informações, pois outros animais têm linguagens até bastante elaboradas para fazerem isso, e sim "a capacidade de transmitir informações a respeito de coisas que não existem", ou seja, a ficção. Quando os humanos 
dominaram essa linguagem mais elaborada, surgiram os mitos, lendas, deuses e religiões, o que ocorreu durante a chamada Revolução Cognitiva (HARARI, 2018, p.32).

Ainda de acordo com esse historiador, a narrativa ficcional permitiu aos humanos a capacidade sem precedentes de um número incontável de estranhos cooperarem entre si de um modo flexível e é por isso que os sapiens governam o planeta atualmente. Um macaco, por exemplo, jamais daria a sua banana sob a promessa de receber bananas ilimitadas após sua morte no céu dos macacos. E foi essa capacidade de cooperação coletiva flexível entre uma quantidade quase infinita de estranhos, desenvolvida por meio da ficcionalidade coletiva, que permitiu que as sociedades se organizassem em cidades, estados etc. Isso porque, toda organização humana em larga escala se baseia em mitos compartilhados que só existem na imaginação das pessoas. $\mathrm{O}$ próprio conceito de Estado decorre de um mito nacional compartilhado (cf. HARARI, 2018).

Basicamente, a narrativa ficcional representa tudo o que nós somos e como nos entendemos atualmente. Esse autor faz uma ressalva, porém, que contar histórias que convençam todos os demais a acreditarem nela não é fácil (HARARI, 2018), entretanto, como temos observado, cada vez mais se busca desenvolver e/ou aprender as melhores técnicas de fazê-lo, ou seja, de se contar narrativas que mobilize o outro em favor daquilo que quem conta a história deseja.

Quanto às questões que se colocam a respeito desses cursos de escrita criativa e do material semelhante a eles, se a literatura é passível de ser ensinada e de qual tipo seria essa literatura, são interessantes mas, cujas respostas cabem, provavelmente, à reflexão individual de cada um. Por um lado, tem-se a crítica da homogeneização da produção artística literária ou, nas palavras de Frederic Jameson (2013, p. 193) referindo-se a esses cursos nas universidades, "suplemento artificial à vida real", por outro lado, não é incomum autores consagrados apontar terem buscado em outros autores referências para a construção de sua própria obra literária, como é o caso do Nobel Gabriel Garcia Marques (2003) em sua obra autobiográfica Viver para contar, quando afirma ter esmiuçado a obra $\mathrm{O}$ som e a fúria, de Faulkner, a fim de aprender sobre o gênero ficcional.

Dawson (2005) propõe uma reflexão interessante sobre esse assunto na introdução do seu livro Creative Writing and the new humanities, a qual, por demasiado extensa e por não ser foco desse artigo, não abordaremos neste texto. McGurl (2011) coloca que tais cursos institucionalizados se construíram no espaço entre liberdade e necessidade, apontando, em sua opinião, que, se por um lado nada pode ser mais restritivo que o sistema educacional na moderna escola americana, por outro lado, na visão de realização pessoal pelo aprendizado, "vamos à escola, ou somos forçados a ir, para nos tornarmos versões mais enriquecidas de nós mesmos" (MCGURL, 2011, p. 3).

Sem dúvida, são relevantes os questionamentos como: se um curso desses, de escrita criativa, limitaria, restringiria um escritor ou poderia ser a base para que ele se tornasse uma versão melhor de si mesmo. Se a escrita, no sentido literário, ficcional, pode ser ensinada ou debatida sem prejuízo à imaginação, à criatividade individual. Ou se ensino da escrita narrativa em instituições como universidades pode ser uma ferramenta útil ao escritor. Todavia, entendemos que importa considerar de fato é que esses cursos já são uma realidade presente e crescente, principalmente no mundo anglófono, mas também no Brasil, onde ainda são incipientes. E, diante disso, como profissionais das letras que poderão vir a ensinar em cursos dessa natureza ou a comentar os cursos dessa natureza, a forma como faremos isso é ainda mais relevante que os questionamentos anteriores, pois seremos nós que iremos determinar o rumo que esses cursos tomarão aqui no Brasil. 
Se por um lado as técnicas narrativas discutidas nesse estudo podem, em grande parte, determinar quais textos sobreviverão no mundo atual, é importante conscientizarmos nossos alunos da existência dessas técnicas e da capacidade de apelo à atenção do outro que exercem, bem como é preciso deixar claro que há muito mais a respeito da escrita narrativa além dessas técnicas. Há muitas outras formas de se expressar de modo narrativo. Em outras palavras, em nossa opinião, duas são as principais questões que importa considerar: 1) por mais que essas técnicas possam ser ensinadas em sala de aula, outras devem ser igualmente contempladas, a fim de que se compreenda que a escrita narrativa não se resume a essas técnicas de apelo ao leitor, já que outras existem em textos de inestimável valor e outras ainda podem vir a existir se, como dizia Pessoa, 'a alma não for pequena'; 2) a segunda colocação que fazemos é a respeito do evidente poder da narrativa, muito maior do que poderíamos ter imaginado quando iniciamos essa pesquisa. Como vimos, a narrativa nos constituiu como humanidade e como sociedade atualmente, e a única razão para essas técnicas narrativas estarem sendo tão exploradas pelo mundo do marketing é por funcionarem e funcionarem muito bem (XAVIER, 2015, AUTORA, no prelo).

Por isso, é preciso entendermos com clareza que tudo aquilo que for colocado em uma boa narrativa tem imenso potencial de existir no mundo de amanhã, logo, a reflexão a respeito de quais valores, crenças e realidades desejamos para o mundo de amanhã e quais devem ser prestigiados nas narrativas nos parece também cabível, pois, por mais apaixonados que sejamos por literatura em todas as suas possibilidades, ainda vivemos no mundo de realidade além delas. Assim sendo, do nosso ponto de vista, é preciso pensar sim no que desejamos propagandear para o grande mundo lá fora. É preciso sabermos em qual mundo desejamos viver amanhã, pois ele está sendo construído desde hoje por meio das nossas narrativas, grandes ou pequenas, publicadas no nosso story das redes sociais ou em grandes veículos de mídia.

\section{REFERÊNCIAS}

BARTHES, Roland. Introdução à análise estrutural da narrative. In Análise estrutural da narrative. Petrópolis, Editora Vozes, 7a ed, 2011.

CAMPBELL, Joseph. O herói de mil faces. São Paulo, editora Pensamento. 2007.

CERVATES, Miguel. Dom Quixote de La Mancha. Volume 1. Rio de Janeiro: Ediouro, 2002.

DAWSON, Paul. Crative writing and the new humanities. Oxon and New York, Routledge, 2005. 254 p.

HARARI, Yuval. Sapiens Uma breve história da humanidade. 34 ed. Porto Alegre, L\&PM, 2018.

JAMESON, Fredric. O segredinho inconfessável da América. Serrote. IMS, 13, 193 209, março 2013.

MCSILL, James. e FREGONESE, Nano. Book in a Box. Técnicas básicas para estruturação de romances comerciais - cena e estória. São Paulo, DVS Editora, 2013.

MCSILL, James. e PRIETTO, Camila. Book in a Box - técnicas básicas para estruturação de romances - personagem, ponto de vista e filtros de cena. São Paulo, DVS Editora, 2013.

MCSILL, James. e PRADO, Mario. Book in a Box - técnicas básicas para estruturação de romances comerciais. A preparação do escritor e revisão da primeira versão. São Paulo, DVS editora, 2013. 
MCGURL, Mark. The program era: Postwar fiction and the rise of creative writing. London: Harvard University Press, 2011.

MEYER, Marlyse. Folhetim: uma história. São Paulo, 2. ed., Companhia das Letras, 2005. $476 \mathrm{p}$.

VOGLER, Christopher. A jornada do escritor - estrutura mítica para escritores. São Paulo, Aleph, 3a ed. 2015.

XAVIER, Adilson. Storytelling - histórias que deixam marcas. Rio de Janeiro, best business, 2. ed., 2015. 